\title{
PROSPECÇÃO DO POTENCIAL MUTAGÊNICO DO EXTRATO AQUOSO DE Myrsine coreacea A PARTIR DE BIOENSAIOS
}

\author{
Thammyres de Assis Alves ${ }^{1}$ \\ Marina Santos Carvalho ${ }^{2}$ \\ Maikon Keoma da Cunha Henrique ${ }^{3}$ \\ Thayllon de Assis Alves ${ }^{4}$ \\ Milene Miranda Praça-Fontes ${ }^{5}$
}

\begin{abstract}
Resumo: O estudo do potencial alelopático dos extratos e óleos essenciais das plantas tem se mostrado importante, já que tais produtos podem ser utilizados na produção de fármacos e de defensivos agrícolas. A Myrsine coreacea é reconhecida por suas propriedades químicas e suas atividades biológicas, porém seu potencial alelopático ainda não foi estudado. Uma maneira de avaliar o potencial alelopático de uma espécie é através de bioensaios, tendo a Lactuca sativa e o Sorghum bicolor como modelos vegetais para tais testes. O objetivo do presente trabalho foi avaliar o efeito fitotóxico e citotóxico de diferentes concentrações do extrato aquoso de M. coreacea utilizando como modelo vegetal L. sativa e S. bicolor. Para isso foram realizadas avaliações fitotóxicas e citotóxicas de quatro concentrações do extrato aquoso de M. coreacea, sendo os dados acessados submetidos ao teste de Dunnett com 5\% de significância. Os resultados demonstraram o potencial alelopático do extrato nas diferentes concentrações, tendo como mecanismos de ação do tipo clastogênico e aneugênico.
\end{abstract}

Palavras-chave: Alelopatia; Alface; Citotoxicidade; Fitotoxicidade; Sorgo.

\footnotetext{
${ }^{1}$ Mestranda em Genética e Melhoramento/Universidade Federal do Espírito Santo, Centro de Ciências Agrárias e Engenharias, Brasil, Alegre/ES. E-mail: thammyresalves@gmail.com.

2 Doutoranda em Genética e Melhoramento/Universidade Federal do Espírito Santo, Centro de Ciências Agrárias e Engenharias, Brasil, Alegre/ES. E-mail: marinasantosufes@gmail.com.

3 Engenharia Florestal/Universidade Federal do Espírito Santo, Centro de Ciências Agrárias e Engenharias, Brasil, Alegre/ES. E-mail: maikond2@gmail.com.

${ }^{4}$ Agronomia/Universidade Federal do Espírito Santo, Centro de Ciências Agrárias e Engenharias, Brasil, Alegre/ ES. E-mail: thayllonalves@gmail.com.

5 Professora Adjunta/Universidade Federal do Espírito Santo, Centro de Ciências Exatas, Naturais e da Saúde CCENS-UFES/Departamento de Biologia, Alegre/ES. E-mail: milenemiranda@yahoo.com.br.
} 